\title{
Higher Education Mergers in China: Lessons for Tanzanian Higher Education Institutions
}

\author{
Robert Lucas Kaniki* \\ Institute of Education, Xiamen University, China \\ Vincent M. Chefor \\ College of Foreign Languages and Cultures, Xiamen University, China
}

\begin{abstract}
Today, China stands out as a good example in terms of higher education institutional mergers, given its accumulated experience and great number of cases of university mergers compared to other countries around the world. This Paper aims to examine mergers in Chinese higher education institutions (CHEIs) by reviewing and analyzing an extensive body of literature on these CHEI mergers and drawing lessons for Tanzanian higher education institutions (THEIs). The study also aims to closely examine some critical aspects of CHEI mergers such as merger policies and restructuring strategies. From the analysis, the study uncovers five CHEI merger solutions, including: Joint Construction, Institutional Amalgamation, Cooperative Administration of Institutions, Transfer of Jurisdiction and Participation of Other Social Sectors in Institutional Operation, from which THEIs can draw inspiration as they lead to academic programs benefits, improved student enrollment, personnel benefits, educational quality enhancement, and financial resource benefits. It is hoped that this study will contribute to narrowing the research gap in university merger studies. It also has a potential to better assist higher education institutions, decision-makers, policy-makers and other higher education stakeholders in planning and implementing higher education merger policies.
\end{abstract}

Keywords: Higher education mergers, Institutional Mergers, CHEIs, THEIs, Merger policies

DOI: $10.7176 /$ RHSS/11-2-09

Publication date: January $31^{\text {st }} 2021$

\section{Introduction}

Higher education mergers have become an important phenomenon for some national governments in their quest to resolve the number of problems facing higher educational institutions such as quality of education, institutional fragmentation, financial difficulties, academic viability, institutional efficiency, and external threats, particularly those related to global competitiveness (Harman \& Harman, 2003). In the higher education sector, a sizable body of literature defines mergers as a distinctive form of inter-institutional cooperation. It also describes mergers as a transfer of ownership in which one or both entities legally disappear and re-emerge as a new entity which has common ownership of the assets of the former organizations (Cai \& Yang, 2015; Harman 1989; Lang 2002; Goedegebuure 1992).

Since the 1960s, many nations around the world have considered higher education mergers as a significant tool in carrying out the reform of their higher education systems. Several examples of mergers abound worldwide, including: the Dutch hogescholen (HBO) reform mergers in the 1980s and 1990s, the restructuring of Norwegian colleges through mergers in 1994, the Finish government's establishment of polytechnics, from 1991 to 1995 , through the upgrading and merging of some advanced vocational schools. Also, the establishment of polytechnics in the UK and colleges of advanced education in Australia all occurred as a result of merger processes in the higher education systems of these countries, with the aim of resolving the problems of fragmentation and duplication within their respective educational sectors (Cai \& Yang, 2015; Goedegebuure, 1992; Kyvik 2002)

The experience of Mergers in Chinese higher education institutions (CHEIs) started in the 1990's when the State Council and the State Educational Commission in China required colleges and universities to improve upon their management system and quality of education (Huang, 2003). The institutions involved were small in size, narrow in specialization and low in terms of professional level. This plan was intended to enhance educational quality, improve institutional efficiency and share educational resources. The plan encouraged individual universities to merge into single comprehensive educational entities so as to have universities with solid academic programs, well-grounded administrative structures, quality, and efficient facilities (Cai, 2013). In spite of criticisms regarding implementation, topographical factors and criteria for evaluating merger outcomes, university mergers as a process in China has brought about substantial results in transforming the Chinese higher education system into a benchmark of world-class universities (Yang, 2015).

Higher education mergers have been a major tool for the restructuring of Chinese universities. Chinese university mergers do not just transform the number of institutions involved into newly-founded institutions but there is also a change in policy, structure and administrative system (Ouyang, 2004). In an era of economic globalization, the Chinese government initiated a huge restructuring of higher education institutions aimed at 
enhancing quality and administrative competence, as well as creating world-class universities for the 21 st-century (Cai, 2007; Huang, 2003; Wan, 2008). This process of Chinese university amalgamation mainly took place during the period 1990 - 2005, although few merger cases were recorded in the decade prior to 1990 (Cai \& Yang, 2015). During this period, more than 1000 CHEIs were involved in merger processes which led to the establishment of over 400 new (see figure 1) (Cai \& Yang, 2015; Huang, 2003).

The first Chinese university to emerge from a merger process was Zhengjiang university of Short-Cycle Programs in March 1992. The university resulted from the merging of three institutions, namely Zhengjiang Vocational College, Zhengjiang Educational College and Jiangsu Broadcasting \& Television University (Huang, 2003). Since then, several mergers have been recorded on a national scale. As indicated in Figure 1 below, in 1992 , fifty-four (54) institutions were combined into nineteen (19) new universities; in 1993 twenty-two (22) institutions were involved in merger processes and only nine (9) new institutions resulted from these processes. The year 2000 stands out as the year that recorded the largest number of merger cases and also the largest number of new institutions established as a result of these mergers; about two hundred and eighteen (218) institutions were involved in merger processes and ninety-one (91) new institutions came into being (Huang, 2003).

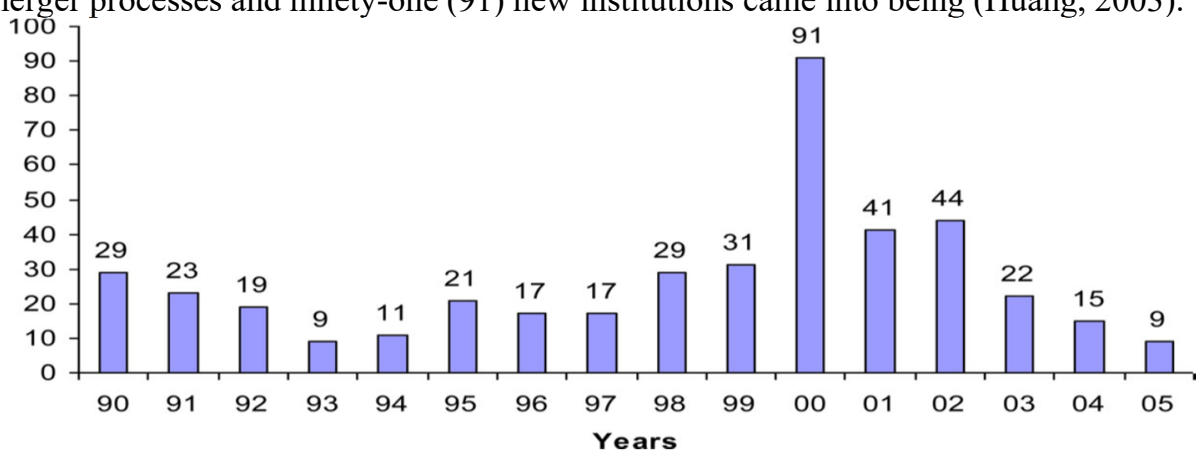

Figure1. Number of newly founded institutions resulting from mergers, from 1990 to 2005. Source: Chinese Ministry of Education www.moe.edu.cn (as cited in Cai \& Yang, 2015).

Initially, the Chinese government acted only as a matchmaker, while the institutions maintained the option to go ahead or not. But later on, the government invested much effort in the sector, thus laying more emphasis on higher education institutional mergers. This impetus led to the amalgamation of many more institutions of the Chinese higher education system. For instance: Sichuan University and Cheng-du Science \& Technology University merged into a single institution named Sichuan University; Jiangxi University and Jiangxi Industrial University also merged into one institution named Nanchang University. Moreover, several Chinese smaller institutions both at provincial and national levels ended up being absorbed by bigger universities. This was the case, for instance, of Beijing Medical University that was absorbed by Peking University; Xi'an Institute of Finance and Xi'an Medical University merged into Xi'an Jiao Tong University; Shanghai Medical University, merged into Fudan University; and many more others (Cai, 2013; Huang, 2003; Yang, 2015).

\section{Problem Statement in Tanzania Higher Education}

The quality of education is essential in the development of any country. It helps to simplify the building of a strong and competitive economy for the county. Education provides the nation with skilled manpower to serve the country's development in various sectors. In Tanzania, the government endeavors to create necessary conditions to provide students with educational access at all levels. At the higher education level, the government has made significant progress, notably, by increasing the number of universities from a single university in the 1970s to more than 51 universities in 2019 which are all accredited by the Tanzanian Commission for Universities (Istoroyekti, 2016; TCU, 2020).

Despite efforts to increase the accessibility of higher education in Tanzania, there are still quite a lot of challenges facing Higher Education Institutions (HEIs). These include the poor quality of education provided in most universities, lack of adequate teaching and administrative staffs, lack of quality academic infrastructure, and limited enrolment in the sciences, engineering and technology (Istoroyekti, 2016; Ndyali, 2016). This is indicative of the fact that, the massive increase in higher education institutions is yet to meet up with the policy to provide quality education in Tanzania, as stated in the country's Development Vision by 2025: "Tanzania should brace itself to attain creativity, innovativeness and high level of quality education in order to respond to development challenges and effectively compete regionally and internationally, cognizant of the reality that competitive leadership in the $21^{\text {st }}$ century will hinge on the level and quality of education and knowledge". Thus, if Tanzanian universities do not resolve the problem of providing quality education that meets international standards, this will inevitably jeopardize the achievement of the targeted Tanzanian Development Vision 2025. An illustration of the magnitude of this concern is the decision, in 2017, by the Tanzanian Commission for Universities (TCU), a government body mandated to recognize, approve, register and accredit universities operating in Tanzania, to 
withdraw its accreditation from two universities among the list of universities in Tanzania due to their failure to meet up with basic standards of education service provision. This move affected 2,046 students, who were obliged to transfer to other higher education institutions in the country. In that same year, TCU banned nineteen (19) institutions of higher education from admitting students for the new academic year 2017/2018 (Kamagi, 2017; TCU, 2020). The decision was announced by the acting Executive Secretary of TCU, Professor Eleuther Mwangeni, during an exclusive interview with The Citizen newspaper in which he said:

As most higher learning institutions start their new academic year today, those which were banned from admitting new students will have to wait the next academic years and, in the meantime, they are required to address the shortcoming [...].The affected universities will be allowed to receive new students from next year, upon satisfaction that they have adhered to the requirements and those who will differ will face legal consequences (Kamagi, 2017)

Apart from imposing a ban on nineteen (19) institutions of higher education for admission of students, TCU also banned twenty-two (22) other higher education institutions from admitting new students in seventy-five (75) academic courses (Kamagi, 2017). In 2019, after several quality assurance based assessments of the nineteen (19) institutions that were banned from admitting new students, TCU released an official report which indicated that only six (6) of them had succeeded in the assessment process and were therefore authorized to admit new students, in limited fields of study, for the 2019/2020 academic year. The rest of the higher institutions were to remain banned until they met the standards of quality higher education provision (TCU, 2020). This situation of disqualifying and blacklisting universities in Tanzania due poor educational standards and efficiency, lack of adequate teaching staffs and proper academic facilities is recurrent in every academic year and is affecting the country's educational system. It also has some consequences on student enrolment across the country. For instance, in the academic year 2017/2018 nearly 33,000 candidates who sat for senior high school national examinations had high scores (Division I \& II), qualifying them for direct entry into universities, and over 22,000 others had average scores (Division III and below) enabling them to seek enrolment in corresponding level institutions (Kamagi, 2017). But, almost half of higher learning institutions were blacklisted for student admissions and others were totally expunged from the list of Tanzanian universities.

Considering the resolute higher education policy of attaining creativity, innovativeness, quality education, and cultivating well trained professional who could be an asset towards the achievement of Tanzania's Development Vision 2025 and realization of the country's dream of industrializing its economy, there are, surprisingly, very few empirical studies on how Tanzanian universities can overcome the multiple challenges mentioned above. This study is therefore prompted by the fact that, if CHEI mergers were a decisive tool in restructuring Chinese universities, enhancing educational quality, improving institutional efficiency and sharing educational resources, then, they can serve as a benchmark for THEIs in their pursuit of almost the same objectives.

\section{Purpose of the Study}

This study aims to provide an insight on the success of higher education mergers by examining the policy, strategies, processes and outcomes of CHEI mergers, which can serve as a benchmark for the improvement of THEIs, thereby helping Tanzania to build quality and competitive university institutions in the Eastern African region.

\section{Research Questions}

To draw lessons from CHEIs mergers, this study uses qualitative questions to examine the topic and issues discussed, with believe that the findings from the review of literature may offer useful insights for bridging the knowledge gap. Thus, we asked two research questions when reviewing and analyzing the literature on mergers in CHEIs and drawing lessons for THEIs.

1. What are the important aspects in understanding higher education mergers?

2. What possible lessons from CHEIs mergers might be useful for THEIs?

\section{Methods}

The review was conducted between May and August 2020. Merriam and Tisdell (2015) posit that, using documentary resources as data is not much different from using interview and observation in qualitative research. This study surveyed documentary resources in English using books, data from the Ministry of Education, official governmental websites and online sources available in several databases such as ERIC, Education Sources on EBSCOhost, ERIC via ProQuest, Google Scholar, Web of Science, just to name few. Databases helped to expand the survey to other peer-reviewed journals and empirical-based articles in scholarly, editorials and book chapters in the areas of higher education, humanities, social sciences, and development. The specific purpose for generating and integrating documents from different sources is to seek convergence through the use of different data sources and to learn more about the topic. In the course of reviewing the documents, authenticity and accuracy were highly considered; for example, originality of the document, rationale of the document, and context of its production 
(Guba \& Lincoln, 1981).

The search terms were higher education, mergers, higher education institution mergers, Chinese higher education institution mergers, Tanzanian higher education system among others. Articles were screened first by title, then by abstract and finally, by full text. Documents that were essentially related to higher learning institution mergers and that helped to answer research questions were the only ones considered.

In analyzing the overall data, skimming (superficial examination), reading (thorough examination) and interpretation were highly engaged. Content analysis was also employed in the study (Glaser \& Strauss, 1967; Merriam \& Tisdell, 2015). Content analysis is the process of organizing information into categories related to the central questions of the research (Bowen, 2009). At this stage every category analyzed from the content was coded to confirming research questions. For instance, all important pieces of information found in the document were assigned to the most relevant categories.

\section{Policy of Mergers in Chinese Higher Education Institutions}

Several reforms such as the economic reform and open-door policy implemented since the end of the 1970s led to the transition from the planned economic system to a socialist market economy system, especially since 1992. In the era of economic globalization, these reforms have conspicuously focused on CHIs, aiming to enhance quality and efficiency, and to introduce CHIs to market mechanisms, thereby ensuring their ranking among world-class universities of the 21 st century (Huang, 2003). It should be recalled that the former systems of CHIs, structured on the Soviet Union model, were criticized for being highly fragmented, with very few specialized professional institutions that could not adapt to the challenges of the 21st Century. The average size of higher education institutions was relatively small and this had some consequences on student enrolment in many key programs. For instance, while the number of CHEIs increased from 404 to 1,016 during the period 1977 to 1985 , the number of students enrolled in universities remained less than 2,000 per university and even less than 1,000 in some of the universities. Moreover, due to the fact that the various institutions were established and administered at central and provincial levels by different educational or administrative services respectively, the limited budget available from government was rather allocated to the many other small scale institutions, given the inefficiency of the higher education institutions (Cai \& Yang, 2015; Hao \&Long; 2000; Huang, 2003; Min, 1994). To solve these problems, CHEIs mergers were among the proactive approaches adopted in the 1990s (Guo, 1998).

Changes in merger policies can be divided into two periods: The first period, from 1950 to 1992, was a period of formulating reform principles; this was the actual drafting phase of the related policies. During this period, although a few cases of small-scale merger processes between higher education institutions could be recorded, there was no concrete government policy on mergers (Huang, 2003). As a result of reforming the Chinese higher education system in the 1950s, higher education institutions were placed under the direct control of different government agencies in China, such as the Ministry of Education, non-educational central ministries and provincial/municipal authorities. The central government was responsible for formulating higher education policies, allocating resources, exercising administrative controls, employing teaching and research staff, developing curricula, choosing textbooks, recruiting students, assigning jobs to university graduates and controlling university finances (Yang, 2015). From 1978 to 1980s, higher education in China experienced another set of reforms. This time, the reforms attempted to develop closer links between the higher education sector and the market. Moreover, due to the increasing proportions of problems of fragmentation and duplication of higher education institutions, the government saw the need for regrouping and realigning CHEIs. In 1985, the Central Committee of the Communist Party of China formulated a document decision on educational system reform to change the central government's tight control over institutions so that these institutions could build closer links to industry and other sectors and foster their own initiatives and capacities to meet economic and social needs. Hence, the administrative system in higher education was reformed into three levels: the central government, provincial governments and central cities (densely populated and economically well-developed cities such as Shanghai and Beijing). Cost recovery measures were thus introduced and higher education became gradually decentralized (Guo, 1995; Huang, 2003; Yang, 2015; Zhou, 2001).

The second period went from 1992 to 2000. During this period more substantial reform policies were introduced to facilitate structural changes in the Chinese higher education sector (Huang, 2003). In 1993 the central government issued the Program for Education Reform and Development in China to reaffirm the 1985 commitment, by the national government, to refrain from direct control over education and rather act as a facilitator (Guo, 1995; Yang, 2015). Hence, the change from a state controlled model to a state-supervised model was experienced in Chinese higher education (Neave and van Vught 1994, Yang, 2015). To make the system more efficient and improve quality of Chinese higher education, a process of CHEIs amalgamation was launched in 1992. However, its origin could be traced back to the restructuring process launched in the 1950s (Yang, 2000; Yang, 2015). In 1993, another major drive for mergers called the national 'Project 211' was introduced. This project was aimed at strengthening around 100 CHEIs as a national priority for the twenty-first century that will improve universities' competitiveness and prestige (Cai \&Yang, 2015). At this period CHEI mergers became 
intensified and carried out earnestly at national level because a clear policy had been established and practical plans existed for the CHEI mergers (Huang, 2003).

\section{Strategic Process in Chinese Higher Education Mergers}

As a response to the rapid increase of mergers in Chinese higher education institutions, a national forum, in 1998, came up with proposals for restructuring and improving CHEI mergers, basically highlighting and recommending the following five major strategies:

Joint Construction: this strategy allows mergers to take place, while financial resources remain essentially the same; but the central and provincial governments each exercise leadership in administering and developing the institutions concerned. The primary goals of joint construction are: firstly, to change or minimize single authority which can help remove barriers between central government and provincial government administrative services; secondly, to build closer relations between institutions and the provinces/cities; thirdly, to help raise funds. By so doing, institutions can have more financial sources to improve their running conditions and enhance their resource allocation. Hence, up to the year 1996, fifty six (56) higher learning institutions had been created under the Joint Construction strategy (Deng 1997; Yang, 2015).

Institutional Amalgamation: Institutional amalgamation refers to the combination of formerly separated institutions in response to new needs. The main objective of initiating this approach is to facilitate the training of merging personnel in view of ensuring efficiency in the improvement of educational quality that will, in turn, enhance institutional strength for further development. To a great extent, this process helped to address issues related to institutional duplications, very small-scale institutions, and the isolation of single-subject institutions. The Institutional Amalgamation process includes: organization of centralized leadership, administration, planning, adjustment of specialization fields, curricula, faculties, and distribution of teaching resources. Hence, up to the year 1996, one hundred and three (103) institutions had been merged into forty-two (42) under this merger strategy (China Education Daily (as cited in Yang, 2015).

Cooperative Administration of Institutions: this process covers a range of collaboration arrangements between different types of institutions operating at a similar level. The cooperation is on a voluntary basis and allows the institutions' financial resources to remain unchanged. This type of co-operation may range from that between two institutions to a multi-institutional co-operation. The aim of cooperative arrangements is to utilize resources effectively, enhancing the advantages that each institution offers, providing interdisciplinary programs, and emerging co-ordination in view of improving educational quality. To measure the effectiveness of this approach, experiments were carried out at several levels in various cities such as Beijing, Shanghai, Guangzhou and Wuhan, resulting in the observation that a good number of institutions had managed to get out of their state of isolation, and made good use of each other's collective resources. By 1997, such co-ordination was extended throughout the country and a hundred and seventy-eight (178) institutions became involved in some types of cooperation. (Deng, 1997; Yang, 2015).

Transfer of Jurisdiction: The transfer of jurisdiction over higher learning institutions took place at various levels: between ministries of the central government, and from higher education office of provincial governments to provincial education commissions. The process plays a key role in reducing dominion over institutions by central and provincial governments in the same area and thus helps to address institutional distribution geographically, and to reduce the waste of educational resources caused by barriers between higher and lower levels in different departments or regions. By 1997 eight institutions under the control of ministries of the central government were transferred to provincial governments (China Education Daily (as cited in Yang, 2015)

Participation of Other Social Sectors in Institutional Operation: Under this approach, the main emphasis is to encourage the participation of enterprises, holding companies and research agencies in the management and administration of institutions in order to promote greater institutional reaction to social demands, to link them closely with enterprises and research institutes, and to strengthen the integration between education, research and production. Statistics show that up to 1997 about 1,744 large and medium-sized enterprises and research institutes participated in this reform with 170 institutions countrywide (China Education Daily (as cited in Yang, 2015)

\section{Lessons for Tanzanian Higher Education Institutions}

There is no doubt that CHEI mergers have a far-reaching influence on China's higher education and provide numerous positive outcomes in terms of academic management, structuring of higher education, and diversification of the academic profile. After carrying out an extensive review of literature on Chinese higher education institution mergers, this study highlights a number of positive features which have been beneficial to Chinese higher education, and which could be successfully implemented in THEIs, thereby serving as a model for development in higher education.

\section{Benefits in terms of academic program design}

One of the purposes of Higher education mergers is to form better academic institutions, which can create more multidisciplinary course programs (Skodvin, 1999). This goal has been achieved in great extent by CHEIs. From 
the launching of the series of ambitious initiatives by the government, University mergers have significantly enhanced academic capabilities and reformed the national innovation system, by increasing several national academic programs in both teaching and research. The designing of a more comprehensive range of academic programs has always being taken into consideration in every stage of the merger processes. For example, in the mid-1990's the focus was to structure and improve humanities, law and business schools within new merged universities. Hence, students began to be introduced to several new programs such as international affairs, history of science, scientific English etc. (Huang, 2003). In 1999, Shanghai Agriculture College merged into Shanghai Jiatong University, which developed collaboration in scientific research and later created a school of life sciences, offering broad opportunities to students (Cai, 2013). Many Chinese universities have now become comprehensive universities, offering courses in almost all areas of study, including most of the key research units and experimental centers.

\section{Benefits in terms of students' enrollment}

The expansion of academic programs within Chinese universities has been accompanied by a rapid rise in student enrollment in different disciplines. Upon completion of the merger processes, the Ministry of Education in China and educational departments in local authorities operated more of the administrative systems while individual institutions played the great role in improving students' enrollment in their respective universities through the introduction of multidisciplinary course programs which attracted more students (Rui, 2015; Huang, 2003). Prior to the mergers, there was a mushrooming of many HEIs, with an average of them being relatively small in size, narrow in specialization and low in terms of professional level, thus being unable to enroll many students (Cai \& Yang, 2015;Min 1994; Yang, 2015). For instance, during the period of 1977-1985 when China experienced a high increase in the number of HEIs from 404 to 1016, the average number of enrolments per institution remained at less than 2000, and more than one-third of institutions had student enrolments of less than 1000 (Cai \& Yang, 2015; Min 1994). To remedy the situation, CHEI mergers were adopted in the 1990s to improve efficiency and build more comprehensive CHEIs (Cai \& Yang, 2015; Guo 1998). Moreover, many universities also started to offer a number of bachelor and graduate programs, which attracted many foreign students to join Chinese universities. In 2003 alone, the number of foreign students in China reached 77,715, from 175 countries (Huang 2007). The latest statistics from China's Ministry of Education reports that a total of 489,200 international students enrolled in Chinese institutions in 2017, representing an increase of $10.5 \%$ in comparison to $7 \%$ in 2015 . This is an important step toward the country's long-term goal of hosting 500,000 students by 2020 (MOE, 2018).

\section{Benefits in terms of personnel development}

The merging of CHEIs into large organizational structures has been a booster in terms of staff quality because bringing staff members from several departments together has helped to pool together a number of competent staff in a given discipline. Also, it has been a morale booster for these staff, finding themselves in a conducive and collegiate academic environment. Study departments are being able to redesign positions and organizational structures that serve the newly merged institutions in a more efficient way. (Huang, 1999). Furthermore, the creation of new academic programs and departments in CHEIs, in 1992, led these CHEIs to begin reforming their staff recruitment policies in universities on the basis of openness, excellence and equal competition. The goal of this recruitment system was therefore reasonable as it allocated qualified personnel based on the combination of responsibilities, rights, and benefits (Gu, Li \& Wang, 2009). Considering the numerous reforms in CHEIs, mergers as one of these reforms contributed a great deal to the improvement of staff quality and quantity. In 2006 the number of staffs in CHEIs was 2,058,461, both full-time teachers, administrative personnel, supporting staffs, workers and others (Wang et al, 2009).

\section{Benefits in terms of quality enhancement}

The entire process undergone by Higher Education Institutions in China has been aimed at improving the structure, distribution, quality, and efficiency of Chinese higher education. The five major restructuring strategies upheld in this process included joint construction, cooperative administration of institutions, transfer of jurisdiction, Participation of other social sectors in institutional operation and CHEI mergers. (Yang, 2015). University mergers became a popular measure in response to the demands for greater efficiency and quality education since it contributes much to the quality of high education in China as evidenced by the rapid increase of student's enrollment from 7.53 million in 1998 to 9.53 million in 1999, the improvement of high education resources such as staff, facilities, dormitories, dining halls, classrooms, and libraries (Yang, 2009). In order to ensure the quality of CHEIs in 1998, university mergers began to be linked to China's bid to achieve world-class status for its universities. For instance, during the celebration of Peking University's centenary in May 1998, the Chinese President and the General Secretary of the Chinese Communist Party elaborated the government's policy of education and science to reform the nation and called for China to establish world-class universities. Under this guiding idea, more and more national higher education institutions participated in mergers and several provincial institutions thus merged into national major institutions (Yang, 2015).

\section{Benefits in terms of resources mobilization}

CHEI mergers have also influenced China's higher education in terms of academic resources mobilization. The 
sector has recorded a lot of positive outcomes in resource management, such that collection and combining of materials from several higher education institutions has led to the establishment of large repositories that no single institution could afford all alone. Institutional libraries are a case in point, with increased number of volumes, books, and other library resources, making library collections more comprehensive and more volatile than when they were located separately. Access to a greater number of library resources is definitely a plus for all merging libraries (Huang, 1999). Moreover, resource sharing has taken center stage, contrasting sharply with the situation that prevailed prior to the advent of mergers whereby, due to various reasons, sharing was a good theory that had never been put into practice. Although several colleges and universities in the same geographic areas talked about resource sharing for years, they had never taken any concrete actions (Wan, 2008). CHEI mergers therefore enabled Universities to make a qualitative leap forward into resource sharing and many hitherto less circulated resources became accessible to the larger university community, with some special collections demonstrating their values for meeting a variety of user needs (Xue, 2006).

\section{Conclusion}

Some records show that CHEI merger processes have also received criticism from few participating institutions for whom the prime goal of the reform is to reduce the number of higher education institutions. CHEI mergers, as a process, was designed to adapt the higher education system to changes in the social environment, so that it could, more directly, serve socio-economic development needs through highly planned, well-organized reforms; improve institutional development through a restructuring of the higher education system; create comprehensive universities to improve operational efficiency and the output quality of the higher education system. Another major impetus for the reform was the resolve to create a group of world-class universities. Achieving all these objectives required great reforms which are now evident in the amalgamation of CHEIs. The combined outcomes of such reforms clearly offer interesting contrasts and take-home lessons to THEIs and to the higher education sector of several other countries in the world. Hopefully, this study provides a basis upon which further qualitative and quantitative research on higher education mergers can be developed and increases chances of gaining the theoretical and practical understanding needed around, especially for regions such as Africa still faced with several challenges in higher education.

\section{References}

Arnolds, A., Stofile, N., \& Lillah, R. (2013). Assessing the outcomes of the higher education mergers in South Africa: Implications for strategic management. Act of Commercial. 13(1), 11-75. http://dx.doi.org/10.4102/ac.v13i1.175

Brender, A. (2003). The big shrink: As enrollments dwindle in Japan, universities begin to merge. The Chronicle of Higher Education

Bowen, G, A. (2009). Document Analysis as a qualitative research method. Qualitative Research Journal, 9(2), 27-40. Doi 10.3316/QRJ0902027.

Buono, A \& Bowditch, L. (1989). The human side of mergers and acquisitions. San Francisco, CA: Jossey- Bass

Cai, Y., \& Yang, X. (2015). Mergers in Chinese higher education: lessons for studies in a global context. European Journal of Higher Education. Retrieved from http://dx.doi.org/10.1080/21568235.2015.1099458

Cai, Y. (2007). Academic staff integrations in post-merger Chinese Higher Education institutions. Tampere university press.

Cai, Y. (2013). What can we have learned from mergers in Chinese Higher Education? Paper presentation on 27 September 2013, in Moscow

Cao, R. (2006). Kuozhao yu jiuye (Enrollment expansion and employment). Retrieved from http://www.cc.org.cn.

Chambers, S. (1987). The merger between private colleges: an empirical analysis. The University of Rochester.

Chen, C. (2002). The research on the administration of multi-campus. Research on education at Tsinghua University. Beijing

Coffman, L. (1996). A Description of merger applied to the Montana State University Context. Journal of the Association for Communication Administration (JACA)

Deng, X. C. (1997). A review of the reform of higher education structure. Higher Education Research in China, 1(1): 18-31.

Eastman, J., \& Lang, D. (2001). Mergers in higher education: Lessons from theory and experience. Toronto: University of Toronto Press.

Glaser, B., \& Strauss, A. (1967). The Discovery of Grounded Theory: Strategies for Qualitative Research. Mill Valley, CA: Sociology Press.

Goedegebuure, L. (1992). Mergers in Higher Education: A Comparative Perspective. Utrecht: Lemma.

Goedegebuure, L. (2012). Mergers and More: The Changing Tertiary Education Landscape in the $21^{\text {st }}$ Century. Oslo: Faculty of Educational Sciences, University of Oslo.

Goolam, M. (2011). Higher Education in Africa: Facing the Challenges in the 21st Century. International higher 
education, (8)63: 20-21

Guba, G., \& Lincoln, S. (1981).Effective evaluation: Improving the usefulness of evaluation results through responsive and naturalistic approaches. The Jossey-Bass higher and adult education series

Guo, Q. J. (Ed.). (1995). A collection of education laws in the People's Republic of China. Beijing: Beijing Broadcasting Institute Press. (In Chinese).

Guo, B. (1998). The current status of higher education administration system and exploration of merger models (In Chinese). Coal Industry Higher Education 998(4): 21-23.

Harman, G.,\& Harman, K. (2003). Institutional mergers in higher education: Lessons from international experience. Tertiary Education and Management

Hao, W., \& Zhengzhong L. (2000). Chinese Higher Education History (In Chinese), People's Republic of China. Haikou: Hainan Publishing House.

Huang, F. (2007). Internationalization of Higher Education in the Era of Globalization: What have been its Implication in China and Japan? Journal of Higher Education Management and Policy,45(7): 47-60.

Huang, F. (2003). Mergers of Chinese Higher Education Institutions in the 1990s. Daigaku Ronshu (Japanese), No.33, 2003

Istoroyekti, Y. (2016). Issues challenging universities: a case of Tanzanian higher education. Ahmad Dahlan Journal of English Studies, (3)1: 23-45

Kamagi, D. (2017, October 30). Ban on 19 universities to remain in force, says TCU. The Citizen. Retrieved https://www.thecitizen.co.tz/news/Ban--19--universities--remain--force-TCU/1840340-4161494tkr0hjz/index.html

Kyvik, S. (2002). The Merger of Non-University Colleges in Norway.” Higher Education 44 (1): 53-72.

Li, L (2003). Li Lanqing jiaoyu fangtanlu (Interviews on education with Li Lanqing). Beijing: People's Education Press

Merriam, S., \& Tisdell, E. (2015). Qualitative Research: A Guide to Design and Implementation. Jossey-Bass

Min, W. (1994). A Case study of an Institutional Merger in Hubei Province People's Republic of China, IIEP Research and Studies Program: Improving the Managerial Effectiveness of Higher Education Institutions. Paris: UNESCO: International Institute for Educational Planning.

Ministry of Education (MOE), People's Republic of China (2018). Statistics of international students in China in 2018

Retrieved

from: http://www.moe.gov.cn/publicfiles/business/htmlfiles/moe/s5987/201202/131117.html

Neave, G., \& van Vught, F. (1994). Government and higher education relationship across three continents: The winds of change. Exeter: BPC Wheaton Ltd.

Rui, Y. (2015). Institutional Mergers in Chinese Higher Education, Mergers and Alliances in Higher Education, DOI 10.1007/978-3-319-13135-1 7

Skodvin, J. (1999). Mergers in Higher Education - Success or Failure? Tertiary Education and Management

Ouyang, K. (2004). Higher education reform in China today. Policy Futures in Education, 2(1), 141-149

Tanzania Commission for universities (TCU), (2020). List of Accredited Universities in Tanzania. Retrieved from https://www.tcu.go.tz/

Yang, R. (2000). Tensions between the global and the local: A comparative illustration of the reorganization of China's higher education in the 1950s and 1990s. Higher Education, 39(3), 319-337.

Yang, R. (2015). Institutional Mergers in Chinese Higher Education. The HKU Scholar Hub. Retrieved from http://hdl.handle.net/10722/201974

Yuzhuo C \& Fengqiao Y. (2015). Demands and Responses in Chinese Higher Education. Higher Education in the BRICS Countries, Higher Education Dynamics 44, DOI 10.1007/978-94-017 9570- 88

Yuzhuo, C \& Xi, Y. (2015). Mergers in Chinese higher education: lessons for studies in a global context, European Journal of Higher Education, DOI: 10.1080/21568235.2015.1099458. Retrieved from http://dx.doi.org/10.1080/21568235.2015.1099458

Zhou, Y. (2001). Gaodengjiaoyu De Zhongda Gaige Yu Chuangxin (Big Reform and Innovation of Higher Education System), China's higher Education, 1(6), 6-7. 